\title{
Prosopagnosia: a double dissociation between the recognition of familiar and unfamiliar faces
}

\author{
DANIEL R MALONE, HAROLD H MORRIS, ${ }^{*}$ MARILYN C KAY, $\dagger$ HARVEY S LEVIN $\ddagger$ \\ From the Division of Neurosurgery $\ddagger$ and the Departments of Neurology* and Ophthalmology, $\dagger$ University of \\ Texas Medical Branch, Galveston, Texas, USA
}

SUMmary Two cases of a dissociation between prosopagnosia and impaired capacity to match familiar faces were studied. Recognition of familiar faces recovered in the first patient, whereas prosopagnosia persisted in the second patient despite recovery of matching unfamiliar faces and other visuoperceptive skills. This double dissociation is discussed in relation to current views of prosopagnosia.

Prosopagnosia is a rare condition in which recognition of faces is impaired, although the patient can usually identify people by their voice and visual features such as clothing or stature. One formulation postulates an impairment of perceptual classification (within a class of objects) which Whiteley and Warrington $^{1}$ found to be specific for faces. An alternative formulation postulates a memory deficit selective for faces ${ }^{2}$ which Meadows ${ }^{3}$ has attributed to an occipitotemporal disconnection. We report two cases of prosopagnosia with contrasting symptomatology. In the first case the prosopagnosia, but not other visuoperceptive defects, resolved while the second patient remained prosopagnosic despite improvement in other visuoperceptive capacities, including matching of unfamiliar faces.

\section{Case reports}

Case 1 A 64-year-old right-handed male presented to his ophthalmologist complaining of the sudden onset of bilateral visual blurring. Despite improvement, he could not recognise familiar people (including his wife) by sight although he could identify them by listening to their voice. Colours appeared "washed out". He reported topographic disorientation, and while reading he would "get lost" on the page. On admission vital signs were normal. Corrected visual acuity was $20 / 30$ on the right and $20 / 25$ on the left. Pupillary reactions, ocular motility, and optokinetic testing were normal. Goldmann perimetry showed a left

Address for reprint requests: Harvey S Levin, PhD, Division of Neurosurgery, The University of Texas Medical Branch, Galveston, TX 77550, USA.

Received 16 October 1981 and in revised form 27 February 1982 Accepted 9 April 1982 homonymous hemianopsia with some sparing superiorly. The fundoscopic and neurologic examinations were normal. An electroencephalogram (EEG) showed intermittent delta and theta activity in the right occipital area. Computed tomography (fig A) revealed bilateral hypodense lesions of the white matter of both occipital lobes with the one on the right extending into the ipsilateral parietal area. Right vertebral and right carotid angiogram revealed a normal left posterior cerebral artery, while the right posterior cerebral artery was narrowed and there was a reduced number of branches in the regions of the calcarine tissue.

When neuropsychological tests were administered (10, 20 , and 22 weeks following symptom onset) he could readily recognise familiar people by sight, but he still found reading and viewing television quite difficult. Speech was fluent and nonaphasic, and testing disclosed normal linguistic functioning. Wechsler Adult Intelligence Scale (WAIS) Verbal IQ was 133. He obtained a forward digit span of six and backward span of five. Orientation and remote memory were normal. Finger recognition was intact. Consistent with the patient's improved recognition of family members by their facial appearance, he correctly identified 14 of 17 facial photographs of famous statesmen (for example, Roosevelt) and 15 of 17 statesmen from visually degraded photocopies. In contrast, the patient's ability to match photographs of unfamiliar faces ${ }^{4}$ was impaired on both the initial and final tests. Colour naming was mildly impaired (for example, purple was called "blue"), while he could point to basic hues named by the examiner and recall the colour of familiar objects. In contrast, he was unable to name or trace the coloured numbers embedded on the Dvorine Pseudo-Isochromatic Plates ${ }^{5}$ nor could he detect the same numbers on a set of "achromatic pseudo-isochromatic" photocopied plates. Thus, his failure on the colour plates could not be attributed entirely to achromatopsia. The Farnsworth-Munsell 100-Hue Test $^{6}$ disclosed difficulty in ordering of colours that differed principally in hue (error score of 392, 10 

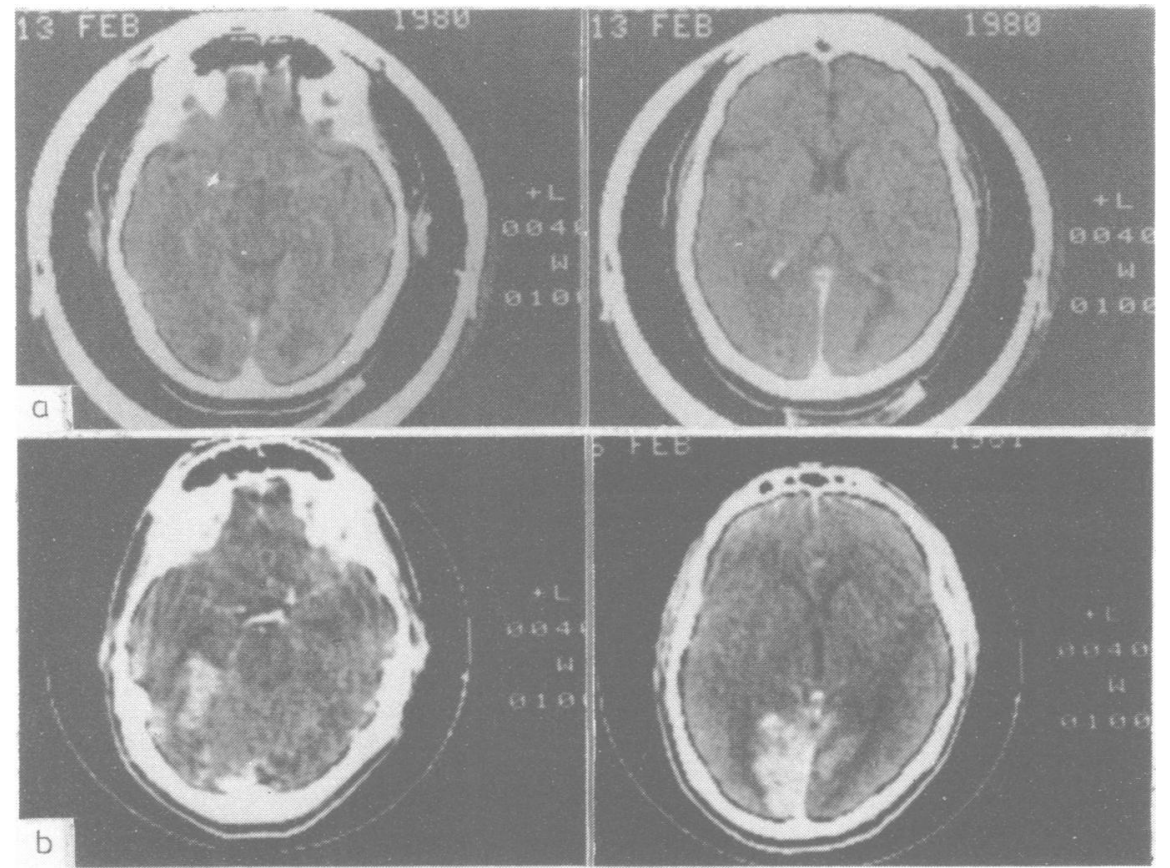

Figure (A) (top two frames) Two months after Case 1 first exhibited visual symptoms, contrast-enhanced computed tomography demonstrated bilateral occipital lobe lesions with the lesion on the right extending to the ipsilateral parietal lobe. The rim of contrast enhancement around the lesions indicates luxury perfusion. (B) (bottom two frames) Contrast-enhanced CT performed on Case 2 three weeks after surgery showed extensive bioccipital and biparietal haemorrhagic infarcts with contrast enhancement.

standard deviations worse than average) but was unlike that associated with congenital colourblindness or diabetic retinopathy. ${ }^{7}$ Patient 1 had mild or no impairment on other visuoperceptive tests. Perception of angularity of lines, ${ }^{8}$ interpretation of road signs and insignias, matching and copying geometric designs and finding embedded figures ${ }^{9}$ were intact. On the Digit Symbol subtest of the WAIS the patient's visuomotor performance was accurate but slow. Visuoconstructive ability was, however, impaired on tests using blocks ${ }^{10}$ or puzzles (WAIS Performance Scale IQ of 72). Visual retention was also persistently impaired for both recall (drawing designs) ${ }^{11}$ and for continuous recognition memory. ${ }^{12}$

Case 2 A 26-year-old right-handed foreman underwent ligation of the left vetebral artery for treatment of an expanding pseudoaneurysm secondary to a gunshot wound sustained seven months earlier. He had no neurological complaints before surgery. When examined 24 hours after surgery he denied seeing light, although pupillary light responses, ocular motility, optokinetic nystagmus, and fundus examination were normal. He was disoriented to place and time, and amnesic for the preoperative period. Motor and sensory examination was normal. The patient's orientation and vision improved over several days, although he was unable to recognise relatives by sight and he lost his way walking around the hospital. On the second postoperative day plain and contrast CT scans demonstrated large lucent areas in both occipital lobes. A contrast CT scan three weeks later showed large haemorrhagic infarctions in both occipital and parietal lobes, involving cortex and white matter (fig B). An EEG revealed bilateral occipital delta activity. Six weeks later his visual acuity was $20 / 15$ in each eye. He demonstrated $1 \mathrm{~mm}$ of anisocoria in bright and dim illumination. The fundi, ocular versions and optokinetic responses were normal. Goldmann perimetry showed a right homonymous hemianopsia plus loss of a section of the left superior quadrant $O U$.

Neuropsychological studies (one, three, and six weeks following surgery) disclosed fluent, nonaphasic speech. Naming objects initially necessitated cuing, but was normal two weeks later as were writing and aural comprehension. ${ }^{13}$ Spelling and reading comprehension for paragraphs were, however, poor. Learning and retention of a list of 12 words remained impaired despite a forward digit span of eight. Recognition memory for titles of past and present television shows was intact. The patient's persistent inability to recognise the faces of relatives by sight at six weeks postsurgery was paralleled by his identification of only five of 22 famous faces (for example, he failed to recognise Jimmy Carter). In contrast, his ability to match unfamiliar faces ${ }^{4}$ improved from an initially defective level to the average range. The patient was consistently unable to name numbers embedded within a coloured dot matrix, ${ }^{5}$ 
although he was able to trace portions of the numbers with his finger. Colour naming, colour concept and pointing recovered by the sixth postoperative week. On our achromatic version of the Dvorine plates he correctly named the numbers on only the five easiest plates. During the sixth postoperative week the Farnsworth Test $^{6}$ disclosed an error score of 492 (12 standard deviations worse than average) and a pattern incompatible with colourblindness. During the first postoperative week the patient was unable to match or copy geometric forms. " These deficits resolved by the third postoperative week at which time he had no difficulty tracing hidden designs. In comparison to the residual visuoconstructive impairment of the first patient, in the sixth postoperative week Case 2 correctly constructed all 10 block designs of the WAIS. Slowing of visuomotor speed (Digit Symbol subtest) was common to both patients. He could not initially draw from short-term memory a single design, " but this improved to five designs correct. Continuous recognition memory remained defective. ${ }^{12}$

\section{Discussion}

Our results corroborate previous findings indicating that recognition of familiar faces is dissociable from matching unfamiliar faces. ${ }^{2}$ Case 1 could not discriminate unfamiliar faces despite resolution of his prosopagnosia. In contrast to the first patient, Case 2 remained prosopagnosic and exhibited memory impairment ${ }^{14}$ despite his improved matching of unfamiliar faces. Only four cases of prosopagnosia with preserved matching of unfamiliar faces have been reported, ${ }^{215-17}$ although CT was not available for clinicopathologic correlation. Impaired visual memory and achromatopsia were prominent findings in both of our patients. Consistent with our CT results, these defects are known to arise from white matter damage to the occipital lobes. ${ }^{18}$ Our finding of a double dissociation between recognition of familiar faces and matching unfamiliar faces is reminiscent of the conclusion reached by Benton ${ }^{19}$ in his discussion of prosopagnosia "that the search for a single basic disability (for example higher level perceptual impairment vs a limited form of memory defect) may be misdirected."

A portion of these findings was presented at the meeting of the International Neuropsychological Society, February, 1981. DR Malone was supported by National Institute of Mental Health National Research Service Award F32 MH08015. This study was supported by NS $07377-11$, Center for the Study of Nervous System Injury.

\section{References}

' Whiteley AM, Warrington EK. Prosopagnosia: A clinical, psychological and anatomical study of three patients. J Neurol Neurosurg Psychiatry 1977;40: 395-403.

${ }^{2}$ Benton AL, Van Allen MW. Prosopagnosia and facial discrimination. J Neurol Sci 1972;15:167-72.

${ }^{3}$ Meadows JC. The anatomical basis of prosopagnosia. $J$ Neurol Neurosurg Psychiatry 1974;37:489-501.

${ }^{4}$ Benton AL, Van Allen MW. Impairment in facial recognition in patients with cerebral disease. Cortex 1968;4:344-58.

${ }^{5}$ Dvorine I. Dvorine Pseudo-Isochromatic Plates. New York: Harcourt, Brace and World, Inc, 1963.

${ }^{6}$ Farnsworth D. The Farnsworth-Munsell 100-Hue Test Manual. Baltimore: Munsell Color, 1949.

' Ramsay WJ, Ramsay RC, Purple RL, Knobloch, WH. Involutional diabetic retinopathy. American Journal of Ophthalmology 1977;84:851-8.

${ }^{8}$ Benton AL, Varney NR, Hamsher K. Visuospatial judgement. Arch Neurol 1978;35:364-7.

${ }^{9}$ Benton AL, Spreen O. Embedded Figures Test. Victoria, BC: Neuropsychology Laboratory, University of Victoria, 1969.

${ }^{10}$ Benton AL, Fogel ML. Three dimensional constructional praxis: a clinical test. Arch Neurol 1962;7:347.

${ }^{11}$ Benton AL. The Revised Visual Retention Test. New York: Psychological Corporation, 1974.

${ }^{12}$ Hannay HJ, Levin HS, Grossman RG. Impaired recognition memory after head injury. Cortex 1979;15: 269-83.

${ }^{13}$ Benton AL, Hamsher K. Multilingual Aphasia Examination. Iowa City: University of Iowa, 1978.

${ }^{14}$ Trillet M, Fischer C, Serclerat D, Schott B. Le syndrome amnésique des ischémies cérébrales postérieures. Cortex 1980;16:421-34.

${ }^{15}$ Assal G. Régression des troubles de la reconnaissance des physionomies et de la mémoire topographique chez un malade opéré d'un hématome intracérébral pariéto-temporal droite. Revue Neurol (Paris) 1969;121:184-5.

${ }^{16}$ De Renzi E, Faglioni P, Spinnler H. The performance of patients with unilateral brain damage on facial recognition tests. Cortex 1968;4:17-34.

${ }^{17}$ Tzavaras A, Hécaen H, Le Bras H. The problem of specificity of deficit of human face recognition in unilateral hemispheric lesion. Neuropsychologia 1970;8:403-16.

${ }^{18}$ Damasio A, Yamada T, Damasio H, Corbett J, McKee J. Central achromatopsia: Behavioral, anatomic, and psysiologic aspects. Neurology (Minneap) 1980;30: 1064-71.

${ }^{19}$ Benton AL. The neuropsychology of facial recognition. American Psychologist 1980;35:176-86. 